\title{
Awakening the Trinity Eye by Walking Through the Triple Spiral Labyrinth
}

\author{
Jai Paul Dudeja \\ Professor and Director, Amity University Haryana, Gurgaon 122413, India. \\ drjpdudeja@gmail.com, Mobile: $91-9312247845$
}

\begin{abstract}
A Labyrinth is a particular pattern, walking through which in a particular way enhances energy, emotional quotient, spiritual quotient, brings peace of mind, freshness, love, compassion etc of the walker. A 'typical' labyrinth sequentially involves the 'preparing' to walk designated path one way towards the centre in the given labyrinth pattern (called 'releasing') followed by spending adequate time in the centre (called, receiving') returning from the centre towards the exit following through the same pathway (called 'returning'), and finally recollecting and recording the experience (called 'journaling') after the walk. In this paper a particular type of labyrinth called the 'Triple Spiral Labyrinth', is discussed. An attempt has been made to establish a correlation of experience between walking through this labyrinth and awakening the 'Trinity eye', for example, the collective consciousness of Brahma, Vishnu and Shiva, in Hinduism.
\end{abstract}

Keywords: Labyrinth, Triple Spiral Labyrinth, Walk, Consciousness, Trinity eye, Hinduism.

\section{INTRODUCTION}

\subsection{What is a Labyrinth?}

The labyrinth is a walking meditation. It is a tool that enables us, in the midst of the busyness of life, to be still and focus our thoughts and feelings. Labyrinths can be found in cathedrals all over Europe and have been used by Christians for hundreds of years as a means of meditation and experience of the Divine Presence. To enter a labyrinth is like entering a cathedral. [1-3]

A labyrinth is a patterned path, often circular in form, used as a walking meditation or spiritual practice. A labyrinth's walkway is arranged in such a way that the participant moves back and forth across the circular (or square or rectangular) form through a series of curves, ending at the Labyrinth's heart or centre. It is unicursal, which means that it has only one entrance and leads in only one direction.

A 'typical' labyrinth sequentially involves the 'preparing' to walk the designated path one way towards the centre in the given labyrinth pattern (called 'releasing'), followed by spending adequate time in the centre (called 'receiving'), returning from the centre towards the exit following through the same pathway (called 'returning'), and finally recollecting and recording the experience (called 'journaling') after the walk. [3]

\subsection{History of Labyrinth}

Labyrinths go back almost 5,000 years, long before Christianity. As with many pre-Christian symbols, the labyrinth was converted for Christian use. As a result, church labyrinths have developed a specifically Christian tradition that dates from the early middle ages. The process began in the fourth century, 11 years after Constantine made Christianity legal. At that time, Roman
Mosaic Labyrinth was placed in a church in North Africa and Christianized by adding the words "sancta ecclesia" (holy church) in the center. The Chartres Labyrinth represents the culmination of the Christian design incorporating the cruciform image, rosette center, and small circles around the perimeter for a lunar calendar to calculate the date of Easter.

According to a report [4,5], the archaeologists have uncovered a labyrinth in India that dates back 2,000 years and has a pattern similar to those found on clay tablets found at Pylos, Greece, from 1200 B.C. The square Indian labyrinth Shown in the following figure), which measures 56 feet ( 17 meters) by 56 feet ( 17 meters), is in Gedimedu near Pollachi and is being excavated by researchers from the Verarajendran Archaeological and Historical Research Centre, of Tirupur, says the Times of India . The site is on an ancient trade route on the east coast that went from Palakkad Gap to Alagankulam.

The Holy Trinity Labyrinth is modeled after the stone Labyrinth embedded in the floor of the Chartres Cathedral, France., in 1220 A.D. Christian pilgrims would walk 20 or 30 miles from their home, ending up on the three-part prayer path in the cathedral. As they walked the winding way out, they felt at one with God, self, others, and nature. This is the three parts of spirituality throughout the ages; known theologically as: purgation, illumination and union.

\subsection{How to Walk the Labyrinth}

In the English language, the words maze and labyrinth are used interchangeably. The labyrinth differs from a maze in that it only has one path and there are no dead ends. The path winds throughout and becomes a mirror for 
where we are in our lives, touching our sorrows and releasing our joys. Walk it with an open mind and an open heart. Quieten your mind and become aware of your breath. Allow yourself to find the pace your body wants to go. The path is a two-way street. Those going in will meet those coming out. You may (pass) people or let others step around you. Do what feels natural when you meet. Allow about one minute between people as you enter the labyrinth.

\subsection{Stages of the Labyrinth Walk}

'Purgation' (Releasing): The act of shedding thoughts and distractions enables you to let go of the details of your life. This is a time to open your heart and quiet your mind.

'Illumination' (Receiving) At the centre, stay there as long as you like, sit or stand, meditate or pray. Allow yourself to receive guidance. [6]

'Union' (Returning) To leave the center, follow the same path back out. There can be a strange sense of strengthening and clarity. You become more empowered to find and do the work you feel you soul calling for.

\subsection{Benefits of Labyrinth Walking}

As a meditative tool the Labyrinth walk can quieten the mind, relax and feel at peace, let go of worries and concerns, cope up with grief and loss, for insight on specific problems, for healing of relationships, to open the flow of creativity, for vocational discernment, for forgiveness, to express thanksgivings to God, recovery from illness or before an operation, to appreciate the beauty of the earth. As an inspirational tool it can shed light on a question or thought. [7]

\section{Triple Spiral Labyrinth}

The triple spiral is a new walking path in the labyrinth world that offers a unique space for play and laughter, wonder and delight, introspection and discovery, questions and answers [Ref. Fig. 1]. Simply put, the triple spiral labyrinth is a reliable way to find what you seek. The pattern contains three spirals and each spiral represents a third of the life cycle. After you enter through the gateway you pass through the spirals from youth to adult to elder, before arriving at the heart space in the centre. Here you pause and reflect before unwinding the spirals in the opposite direction and completing at the gateway.

The triple spiral, or triskele, is a Celtic and pre-Celtic symbol found on a number of Irish Megalithic and Neolithic sites, most notably inside the Newgrange passage tomb, on the entrance stone, and on some of the curbstones surrounding the mound. The Triple Spiral Labyrinth has been present for thousands of years at the ancient sites in the world experiencing the triple spiral walk that creates a strong link with Divine [8]. The human body has seven major chakras - Root, Sacral, Solarplexus, Heart, Throat, Third-eye and Crown. The inward path is walking from the root at the start, through each chakra marked at the spiral turning points - and moving beyond into spirit. The return path is walking with spirit back through the chakras returning to our physical selves.

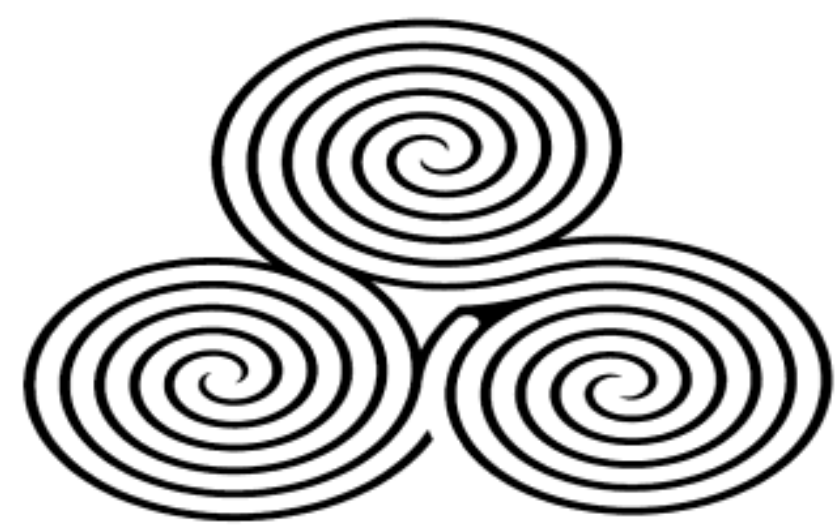

Fig 1: Triple Spiral Labyrinth

\subsection{Origin and Symbolism of the Triple Spiral}

There are many different spiral arrangements containing multiple whorls. The circle, spiral and wheel are all powerful symbols representing death and rebirth, and the seasons of life. Some spirals have an equal number of whorls, or arms, and symbolize balance. The most common of the multi-armed spirals is the triple spiral or triskele [9].

The ancient structure has been found both in preColumbian America and in Bronze Age Europe. In Europe it is especially associated with Celtic Christianity. It is considered to be a sign of female power and especially power through transition and growth.

Each aspect ever flows outward and always returns to the point from which it starts. The beauty of the symbol is that none of its original meaning is known for certain; and we might choose which trinity that holds the most significance for us, or make up our own, as we go.

With the triple spiral labyrinth as your guide, you will enter the quiet place in the centre of your heart and meditate on what to let go and what to claim.

\section{WHAT IS THE MEANING OF 'THIRD EYE'?}

The two eyes in humans merely gather information; they do not "see" in the literal sense they gather input, which the mind then perceives as sight. So it is the mind that does the real seeing, just as it does for hearing, touching and tasting. All the other parts are merely specialized information gathering systems. So to "see" with the third 
eye is to skip the other information gathering systems and use the mind directly.

This takes practice as one might image, as we are trained by the body to use the senses to gather information. Once freed of the limits of the body, the mind is very much able to gather information that the senses cannot perceive.

The location of the third eye, perceived to be in the centre of the forehead; it correlates to the sixth chakras. To open the third eye, is to open oneself to extrasensory perceptions, which is where we get that whole idea from and beyond the senses.

The Third eye "sees' auras, which are invisible to the body's eyes; it sees the colours that surround a person. It can see the 'thought' as if the working of the mind has made a printout for the third eye to read. This is what allows us to see on the astral planes; to see into things and situations where the body's eyes do not function. The Third eye is the part of yourself that tells you all the things that your senses cannot know: how to see another person on the astral planes, how to tell when the phone will ring, how to know the person in front of you does not have your best interest at heart, a million cues of the senses can tell you a lot, but that last bit of information: that tingle in the mind that says: "It means using the third eye!"

Third eye is the centre of the labyrinth of life. Fig. 2 illustrates experientially the awakening of the 'third eye' if one walks through the spiral labyrinth.

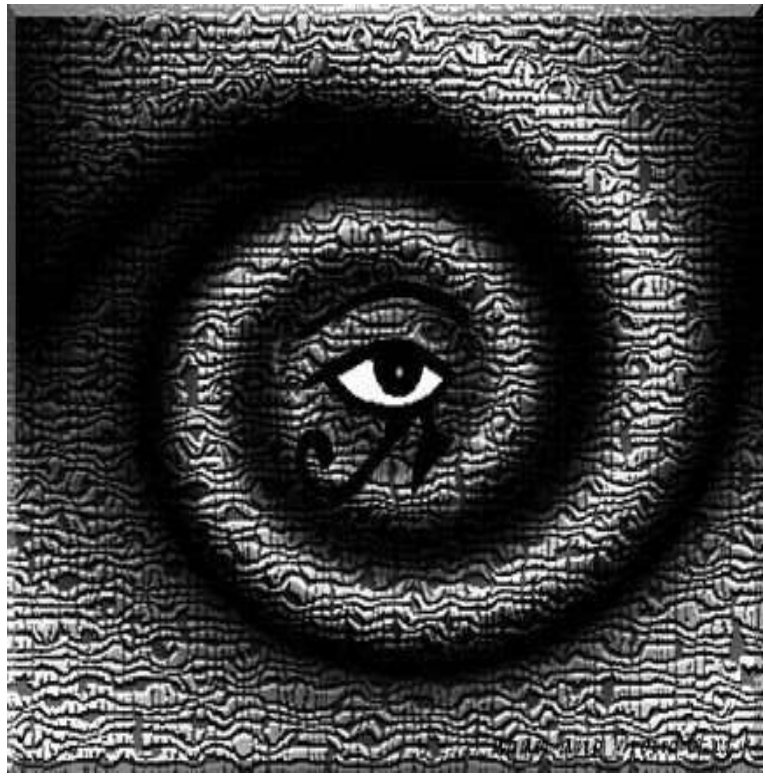

Fig 2: Spiral labyrinth for wakening the 'third eye'

\section{TRINITY}

There are a myriad of three-pronged meanings for the triple spiral, which is sometimes called the spiral of life: Body, Mind, Spirit; Father, Son, Holy Ghost; Mother, Father, Child; Past, Present, Creator (Brahma), Sustainer
(Vishnu), Destroyer (Shiva); Creation, Preservation, Destruction; etc.

\subsection{Trinity in Christianity}

In Christianity, the Trinity is: Father, Son, and the Holy Spirit. The Father is God as the Creator existing beyond creation (Cosmic Consciousness). The Son is God's omnipresent intelligence existing in creation (Christ Consciousness). The Holy Spirit is the vibratory power of God that objectifies and becomes creation. Many cycles of cosmic creation and dissolution have come and gone in Eternity. At the time of cosmic dissolution, the Trinity and all other relativities of creation resolve into the Absolute Spirit."

This Trinity is represented by Fig. 3 below:

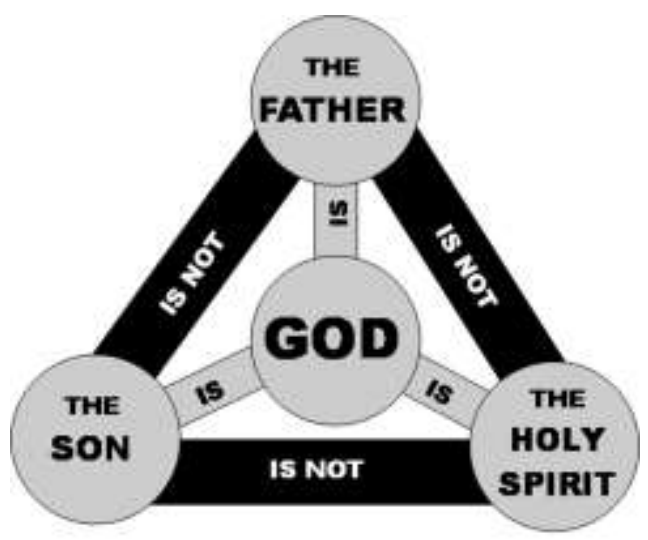

Fig 3: Representation of 'Trinity in Christianity

\subsection{The symbol of 'Trinity Eye' in Christianity:}

Fig. 4 depicts the symbol of the 'Trinity eye' in Christianity:

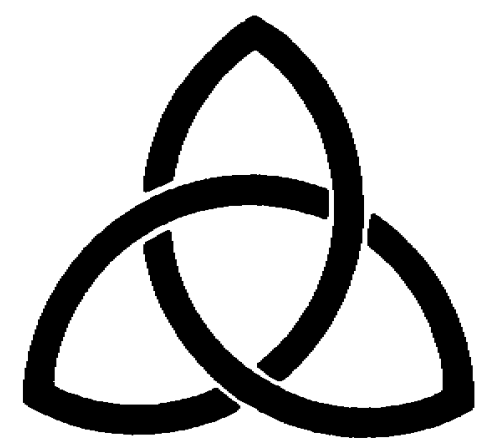

Fig 4: Symbol of the 'Trinity eye' in Christianity

As can be seen from this picture, it resembles the picture of a triple spiral labyrinth, indicating that the walk through the triple spiral labyrinth leads to the awakening of the 'Trinity eye'.

\subsection{Triple spiral labyrinth as a symbol of Trinity}


What the triple spiral or triskele symbol meant to the pagans who built Newgrange and other monuments is unknown. But, as Christianity came into the forefront in Ireland before the 5th century, AD, the triskele took on a new meaning, as a symbol of the Trinity (that is., Father, Son, and Holy Spirit) and, therefore, also a symbol of eternity. Its popularity continues today as a decorative symbol of faith for Christians of Celtic descent around the world. Neopagan religions such as Celtic Reconstructionist Paganism and Wicca use the symbol to represent a variety of triplicities from their belief systems.

The triple spiral is one of the main symbols of Celtic Reconstructionist Paganism, often standing for the "three realms" - Land, Sea and Sky, or for one of a number of deities who are described in the lore as "three-fold" or triadic. The god Manannán is probably most often the one symbolized by the triskele, though some also use it for the goddess Brighid. Some Celtic-inspired Wiccans also use the triple spiral symbol, most often to represent the concept of the triple goddess.

The triple spiral labyrinth, (displayed in Fig. 5) is a wonderful symbol on many levels. It is an ancient preCeltic and Celtic symbol. Though its original meaning is unknown, it was adopted by Christians in Ireland and became a symbol for the Trinity (Father, Son, and Holy Spirit). This image represents the intertwining of God, Jesus and the Holy Spirit and the journey we all travel amongst them.

A new meaning has emerged in the triple spiral labyrinth to "hold space and time for people as they journey toward greater spiritual, emotional, and physical wholeness." The triple spiral labyrinth embodies this journey, reminding us of the inter-connectedness of the spiritual, emotional, and physical aspects of who we are.

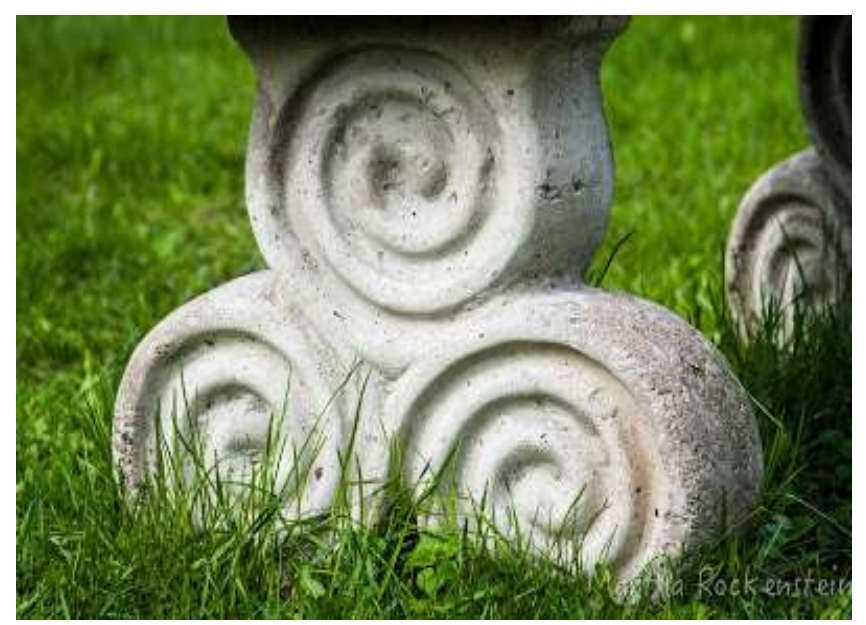

Fig 5: Triple Spiral Labyrinth

\subsection{Trinity (Trimurti) in Hinduism}

Brahma, Vishnu and Mahesh (or Shiva): are considered the highest gods of Hinduism, next only to Brahman
(Atman) in importance and hierarchy. Functionally they represent the triple functions of Manifested Brahman. Hence they are also called the Trimurtis or the Trinity of Hinduism. Brahma is the creator, Vishnu is the preserver and Shiva is the destroyer. They are assisted in their duties, by their consorts, or associated goddesses namely, Saraswati, Lakshmi and Parvati, respectively.

Brahma, Vishnu and Shiva, the triple gods of Hinduism, are different in a limited sense only. They are considered manifestations of the same Supreme God, who is also known as the Saguna Brahman or the awakened or dynamic Brahman. God Himself is considered by the monists as a reflection of Supreme Brahman in (the triple gunas of) Nature. Since ordinary human minds cannot comprehend the oneness of the universe, it becomes difficult for us to understand this concept clearly. God who exists in innumerable planes simultaneously appears as the Trinity in three different roles. The difference, if any, is in appearances which is part of the grand illusion that He weaves all around us.

Fig. 6 is an illustration of Trinity (or Trimurti) in Hinduism:

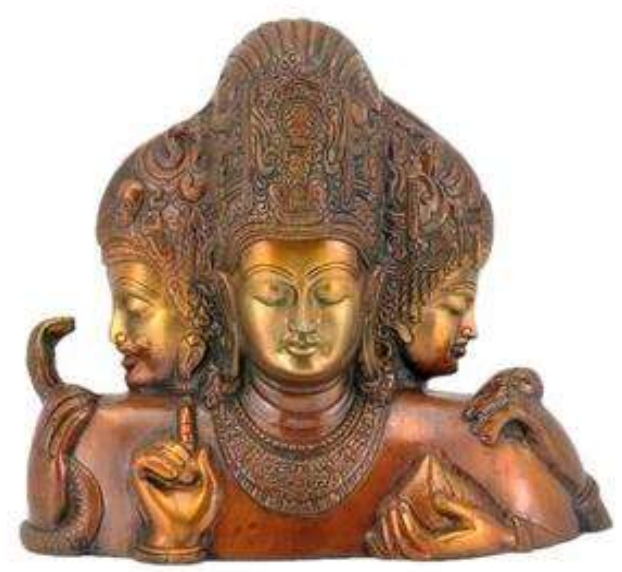

Fig 6: Trimurti (Brahma, Vishnu, Mahesh) in Hinduism

Are these gods are different, the answer is both yes and no. They are different because, from human point of view they perform different tasks and have qualities and energies that differ widely from one another, and also control different worlds that seem to set widely apart. But at the highest level they are the three aspects of the one and the same supreme Reality. Together they are like a mighty flow of energy branching out into three different streams at the point of contact with human awareness.

\section{SIMILARITY OF INTERPRETATION OF TRINITY IN CHRISTIANITY AND HINDUISM}

Let us appreciate the similarity of interpretation of Trinity in Christianity and Hinduism. [11] Before we do so, we note that there is another interpretation of 'Trinity' in Hinduism, which is, Sacchidananda (an elision of the three Sanskrit metaphysical terms, Sat-Chit-Ānanda, 
words individually translated as "Existence" (God), "Consciousness" (the Son), and "Love" (the Holy Spirit). This term, Sacchidānanda, encapsulates the Vedantic metaphysics of the Trinity in texts composed as early as the 4th century $\mathrm{CE}$, and perhaps it is not an accident that it was in this very same century that early Christians in Constantinople (381 CE) codified the doctrine of the Holy Trinity in the Nicene Creed, which has ever since been recited daily by Christians.

\section{SOME REFLECTIONS 'IN THREES' FROM 'TRIPLE SPIRAL LABYRINTH'}

Many theories/experiences/reflections/benefits have been attributed to the meaning and symbolism of the triple spiral labyrinth. Some of the interrelationships that come 'in threes' are:

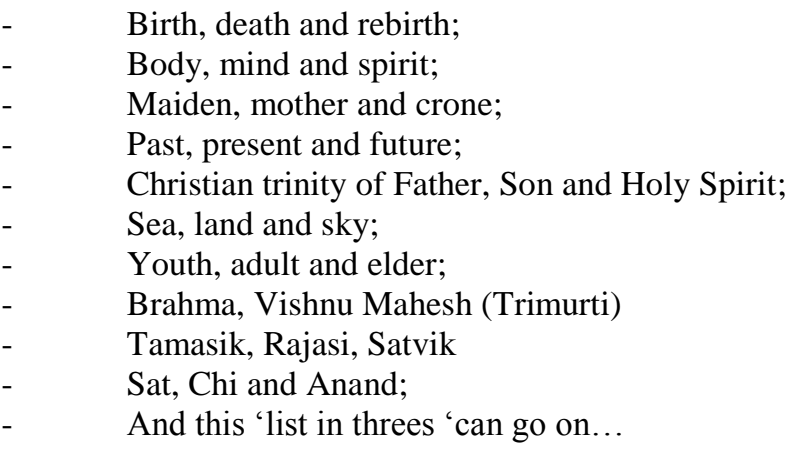

\section{CONCLUSION}

In this paper we have asserted that by walking through a particular type of labyrinth, called the 'triple spiral labyrinth' can lead the walker to the awakening of the Trinity Eye or the Trinity Consciousness. Further, we have seen that this 'Trinity' has got similar interpretation in Christianity as well as in Hinduism. Walking innocently through the triple spiral labyrinth is independent of any religion; all walkers can achieve the same Trinity Consciousness.

\section{REFERENCES}

[1] Kay Sandor, M. and Robin D Froman, "Exploring the Effects of Walking theLabyrinth", J Holist Nurs, Vol. 24, 2006, 103. DOI: $10.1177 / 0898010105282588$.

[2] Artress, Lauren. "Walking A Sacred Path: Rediscovering the Labyrinth as a Spiritual Tool”. New York: Riverhead Books, 1995.

[3] http://www.holytrinitygnv.org/media/28044/Labyrinth-trifold-brochure.pdf

[4] The Times of India, Aug 07, 2015.

[5] Dudeja, Jai Paul, "Labyrinth Walking: Origin, Patterns, Significance, WalkingProcedures and Spiritual Benefits", International Journal of Yogic, Human Movement and Sports Sciences, (ISSN: 2456-4419), Vol. 3, Issue 2, Part K, 2018, pp 666-673.

[6] https://dieweltderansicht.wordpress.com/2013/04/15/lostand-found-in-the-labyrinth/
[7] Artress, Lauren, "The Sacred Path Companion: A Guide to Walking the Labyrinth toHeal and Transform", Penguin Random House, 2006.

[8] Cosán "Trúin, "Tranquil Paths", http://www.tranquilpaths.com/triple-spiral labyrinth.html

[9] labyrinthnetworknorthwest.org/resources/2011/111026_exa miner_Laughing_Flower. pdf

[10] Rockenstein, Martha, "Dancing with the Spirit", http://martha-rockenstein.blogspot.com/2016/05/triple-spirallabyrinth.html

[11] Joye, Shelli, "Trinitarian Metaphysics: A New Approach to Christianity, Indian Philosophy, and Quantum Physics", https://www.academia.edu/35387352/Trinitarian_Metaphysi cs_A_New_Approach_to_Christianity_Indian_Philosophy_a nd_Quantum_Physics 